\title{
Aerosol optical thickness of Mt. Etna volcanic plume retrieved by means of the Airborne Multispectral Imaging Spectrometer (MIVIS)
}

\author{
Claudia Spinetti, Maria Fabrizia Buongiorno, Valerio Lombardo and Luca Merucci \\ Istituto Nazionale di Geofisica e Vulcanologia, Roma, Italy
}

\begin{abstract}
Within the framework of the European MVRRS project (Mitigation of Volcanic Risk by Remote Sensing Techniques), in June 1997 an airborne campaign was organised on Mt. Etna to study different characteristics of the volcanic plume emitted by the summit craters in quiescent conditions. Digital images were collected with the Airborne Multispectral Imaging Spectrometer (MIVIS), together with ground-based measurements. MIVIS images were used to calculate the aerosol optical thickness of the volcanic plume. For this purpose, an inversion algorithm was developed based on radiative transfer equations and applied to the upwelling radiance data measured by the sensor. This article presents the preliminary results from this inversion method. One image was selected following the criteria of concomitant atmospheric ground-based measurements necessary to model the atmosphere, plume centrality in the scene to analyse the largest plume area and cloudless conditions. The selected image was calibrated in radiance and geometrically corrected. The 6S (Second Simulation of the Satellite Signal in the Solar Spectrum) radiative transfer model was used to invert the radiative transfer equation and derive the aerosol optical thickness. The inversion procedure takes into account both the spectral albedo of the surface under the plume and the topographic effects on the reflected radiance, due to the surface orientation and elevation. The result of the inversion procedure is the spatial distribution of the plume optical depth. An average value of 0.1 in the wavelength range 454-474 $\mathrm{nm}$ was found for the selected measurement day.
\end{abstract}

Key words aerosol optical thickness - volcanic plumeMt. Etna - MIVIS - DEM - radiative transfer model $6 S-$ inversion technique

\section{Introduction}

Volcanic plumes are often the most visible indicators of volcanic activity. They are a turbulent mixture of solid particles, liquid droplets and gases exsolved from magma,

Mailing address: Dr. Claudia Spinetti, Istituto Nazionale di Geofisica e Vulcanologia, Via di Vigna Murata 605, 00143 Roma, Italy; e-mail: spinetti@ingv.it emitted continuously from summit craters, fumarolic fields or during eruptive episodes. The direct sampling of volcanic plumes is difficult and often hazardous. The use of remote sensing techniques permits a fast, large-scale and above all safe measurement of the volcanic emissions to study the most variable components of volcanic plumes, such as aerosols.

Volcanic aerosols are defined as minute liquid and solid particles suspended in the atmosphere. They consist of solid sulphur-derived particles, aqueous droplets and volcanic ash; typical size is in the range $10^{-2} \mu \mathrm{m}-10 \mu \mathrm{m}$ (Sparks et al., 1997). Volcanic aerosols have important climatic and environmental effects. Depending on the particle size distribution and on the number 
concentration, sulphate aerosols are able to modify the atmospheric radiative field: they scatter the incoming short-wave solar radiation and absorb the outgoing long-wave radiation (Fiocco et al., 1994).

Different volcanic activities, such as volcanic eruption, volcanic clouds and plumes, inject into the atmosphere volcanic aerosol with different altitudes, latitudes and residence times.

Explosive volcanoes, such as Mt. Pinatubo or Alaskan volcanoes are able to inject large quantities of sulphate aerosol into the stratosphere with a residence time of several years. As several studies have pointed out (Fiocco et al., 1994), large quantities of stratospheric aerosol increase the backscattering of the incoming solar radiation in the short-wave region; the result is the reduction of temperature at the Earth's surface (Hansen et al., 1992).

Conversely, degassing volcanoes produce effusive plumes rich in sulphate aerosol (Sparks et al., 1997) and inject them in the troposphere with residence times, variable from hours to weeks, depending on their altitude and geographical location (Chin and Jacob, 1996).

Tropospheric sulfate aerosols are destructive for the environment as they may cause acid rains and contaminate local water supplies; moreover they are hazardous for local human and animal populations (Neubauer et al., 1996).

Mt. Etna (Sicily) is one of the world's most actively degassing volcanoes (Allard et al., 1991). It is a large strato-volcano with a summit height approximately of $3300 \mathrm{~m}$ a.s.l. and a circumference of about $200 \mathrm{~km}$ at ground level; it produces alkaline and basaltic lava during summit and flank eruptions (Romano and Sturiale, 1982). An important feature of its activity is the continuous and abundant noneruptive gas emissions from the summit craters. This degassing process produces an effusive plume rich in gases $\left(\mathrm{H}_{2} \mathrm{O}, \mathrm{CO}_{2}, \mathrm{SO}_{2}\right.$, $\mathrm{HCI}, \mathrm{H}_{2}, \mathrm{H}_{2} \mathrm{~S}, \mathrm{HF}, \mathrm{CO}, \mathrm{N}_{2}, \mathrm{CH}_{4}$ ) (Francis et al., 1998; McClelland et al., 1989), and aerosols (ash and sulfates) (Amman et al., 1992). The main gas components and mean fluxes are shown in table I (Jaeschke et al., 1982; Symonds et al., 1994).

In quiescent conditions, the $\mathrm{SO}_{2}$ gases released by the magma, rise up in to the atmosphere. During this degassing, aqueous and gas phase oxidation of sulphur species and
Table I. Main gas components of the Etna plume, typical emission rates and the Etna average fluxes compared to global volcanism (Jaeschke et al., 1982; Allard et al., 1991; Symonds et al., 1994).

\begin{tabular}{ccc}
\hline \hline Gases & $\begin{array}{c}\text { Etna fluxes } \\
(\mathrm{t} / \mathrm{d})\end{array}$ & $\begin{array}{c}\text { Etna to global } \\
\text { volcanism } \\
\text { percentages }\end{array}$ \\
\hline $\mathrm{H}_{2} \mathrm{O}$ & 13000000 & $10 \%$ \\
$\mathrm{CO}_{2}$ & 27000 & $7-16 \%$ \\
$\mathrm{SO}_{2}$ & 5500 & $11 \%$ \\
$\mathrm{HCl}$ & 140 & $9 \%$ \\
\hline
\end{tabular}

subsequent nucleation and accumulation of particles in droplets occurs. This process, depending on relative humidity, temperature and environmental conditions (Watson and Oppenheimer, 2000), results in the formation of liquid droplets composed of a solution of water and sulfuric acid known as sulfate aerosols.

Mt. Etna is an ideal test site, given the copious emissions in the troposphere and the easy access compared to other volcanoes.

Volcanic plumes modify the signal measured by an airborne sensor since the incident solar radiation is scattered and absorbed by the molecular and particle plume components. The aerosol optical thickness $\tau^{a}$ is a geophysical parameter which expresses the influence of volcanic aerosol on direct radiation crossing the plume. This parameter is a function of wavelength according to the Ångstrom equation. The two Angstrom coefficients give a rough idea of the particle size and of the total number concentration of aerosol particles, if their refractive index is known.

This work gives a short presentation of the measurements collected during the MVRSS «Sicily 1997» campaign; then a theoretical overview of the inversion algorithm and the corresponding AOD map are presented.

\section{Data set}

In the framework of the «Mitigation of Volcanic Risk by Remote Sensing Techniques» 
Table II. MIVIS spectral bands characteristics (Bianchi et al., 1994).

\begin{tabular}{cccc}
\hline \hline Optical port & Spectral range & $\begin{array}{c}\text { Number of } \\
\text { channels }\end{array}$ & Spectral resolution \\
\hline 1 (VIS) & $431-833 \mathrm{~nm}$ & 20 & $20 \mathrm{~nm}$ \\
2 (NIR) & $1150-1550 \mathrm{~m}$ & 8 & $50 \mathrm{~nm}$ \\
3 (SWIR) & $1985-2479 \mathrm{~m}$ & 64 & $9 \mathrm{~nm}$ \\
4 (TIR) & $8210-12700 \mathrm{~m}$ & 10 & $340-540 \mathrm{~nm}$ \\
\hline
\end{tabular}

(MVRSS) project, funded by the European Community, the «Sicily 1997» field measurements campaign was organized to acquire highresolution hyperspectral remote sensed images with the airborne «Multispectral Infrared and Visible Imaging Spectrometer» (MIVIS) together with ground-based measurements (Buongiorno et al., 1999).

The main targets of the «Sicily 1997» field measurements campaign were: the analysis of plume gas components; the estimation of the $\mathrm{SO}_{2}$ flux (important for the evaluation of volcanic activity (Caltabiano et al., 1994); the spectral characterisation of geological surfaces; the determination of the thermal emissivity of different geological surfaces to study structural characteristics of volcanoes; the estimation of aerosol burden; the realisation of a plume dispersion model.

The MIVIS instrument represents a second generation imaging spectrometer developed for environmental remote sensing studies (Bianchi et al., 1994). It is a Daedalus AA5000 electrooptical scanner with 102 spectral channels simultaneously sampled and recorded. The 4 spectrometers collect radiation reflected by the surface in the visible and infrared spectral range (see table II).

The airborne campaign took place in the week from 11 to 17 June 1997, over Etna, Vulcano and Stromboli. This period was chosen to meet suitable weather conditions since the solar irradiance is near to its yearly maximum, expected relative humidity is low and expected wind direction is $\mathrm{N}-\mathrm{W}$ prevalently. These factors allow the acquisition of good quality images since the area under the plume is well illuminated and, especially in the early morning, the formation of orographic clouds is limited.

Indeed, in this period, the time weather conditions were as expected. The sky was cloudless throughout the week, except for 17 th June. A temperature mean value of $(12.5 \pm 1.5)^{\circ} \mathrm{C}$, a low relative humidity of $35 \% \pm 5 \%$ (except for the 17th June when relative humidity was $42 \%)$, a pressure of $(723 \pm 3) \mathrm{hPa}$, a wind speed between 11 to $20 \mathrm{~m} / \mathrm{s}$ and wind direction of about 300 degree north, was measured at Torre del Filosofo meteorological station (2920 m a.s.l. height) (Buongiorno et al., 1999).

During the campaign, the 3 observed volcanoes presented different activity levels. Mt. Etna was in a quiescent period since the 1996 eruption. It showed a major degassing activity in the N-E crater, a minor one in Bocca Nuova crater and same episodes of lava fountains in the S-E and La Voragine craters. Stromboli (924 m a.s.l. height) showed small eruptions of ashes and lava with a frequency of 2-3 episodes per hour. Volcano (390 $\mathrm{m}$ a.s.l. height) presented fumarole fields and gas emissions located in the Fossa crater.

Images of the Etna plume were taken by 3 flight lines having a radial arrangement, one along the plume axis oriented on E-S-E direction and two along each side. Most of the groundbased measurement sites were located on the south-eastern flank of the volcano, covered also by an additional flight line. Figure 1 shows the MIVIS flight lines scheme over Mt. Etna. The platform altitude was about $6500 \mathrm{~m}$ a.s.l. and the corresponding ground resolution ranged from 4 to $13 \mathrm{~m}$, depending on orography and aircraft altitude. 


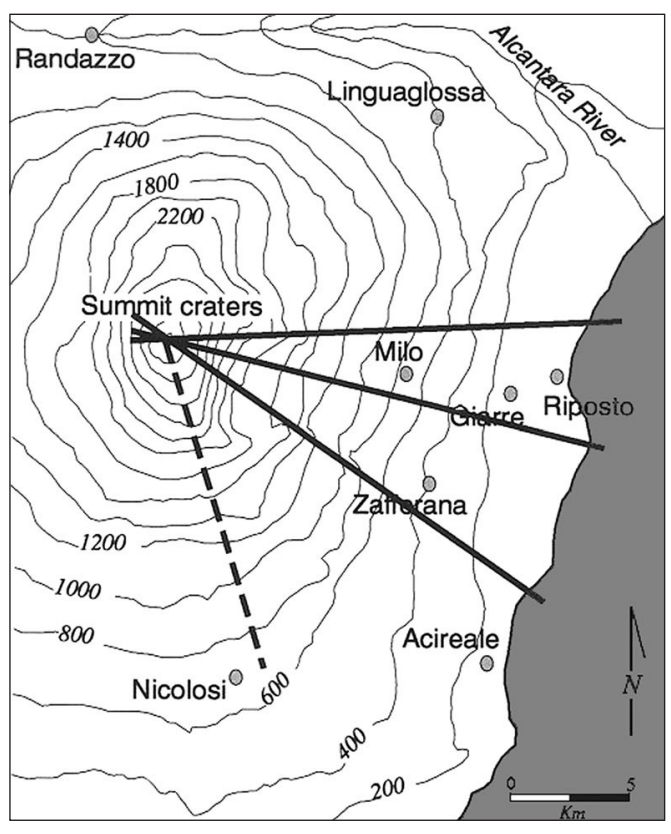

Fig. 1. MVRSS «Sicily 1997» campaign MIVIS flight lines over Mt. Etna. Solid lines: MIVIS flights over the volcanic plume (one along the plume axis and two on each side). Dashed line: MIVIS flight over the groundbased measurement sites.
Different ground-based measurements, derived from atmospheric, radiometric and spectral data, were taken simultaneously to the flights, and are reported in table III (Buongiorno et al., 1999).

\section{Image processing}

To analyse the optical characteristics of the Etna plume, a single digital image has been selected with the following criteria:

i) The plume should be well contained in the image.

ii) The signal-to-noise ratio should be large.

iii) Simultaneous ground-based measurements should be available (atmospheric photometric measurements and vertical profile).

iv) Cloudless conditions should be present.

The image satisfying these criteria was acquired the 16 June. The wind direction was 290 north degree while the aircraft trajectory was about 87 north degree. This imply a difference on same degree between image axis and plume axis. In fig. 2 the selected image is showed. However, no ground-based photometric measurements across the plume were available for this field measurements campaign.

Table III. MVRSS «Sicily 1997» campaign ground based measurements (Buongiorno et al., 1999).

\begin{tabular}{|c|c|c|}
\hline Ground-based measurements & Type of data & $\begin{array}{l}\text { Use in the MIVIS data } \\
\text { analysis }\end{array}$ \\
\hline $\begin{array}{l}\text { Atmospheric vertical profiles with on- } \\
\text { board balloon radiosonde. }\end{array}$ & $\begin{array}{l}\text { Pressure, temperature, relative humidi- } \\
\text { ty, wind direction and speed. }\end{array}$ & $\begin{array}{l}\text { Modelling of the atmospheric } \\
\text { parameters. }\end{array}$ \\
\hline $\begin{array}{l}\text { Sun-photometric measurements with } \\
2 \text { sun-photometer located in different } \\
\text { places. }\end{array}$ & $\begin{array}{l}\text { Total atmospheric optical thickness, } \\
\text { aerosol optical thickness and Ångstrom } \\
\text { turbidity parameters. }\end{array}$ & $\begin{array}{l}\text { Modelling of the atmospheric } \\
\text { optical characteristics. }\end{array}$ \\
\hline $\begin{array}{l}\text { Radiometric measurements with spec- } \\
\text { troradiometer. }\end{array}$ & Atmospheric radiance & $\begin{array}{l}\text { Modelling of the atmospheric } \\
\text { radiative contributes. }\end{array}$ \\
\hline $\begin{array}{l}\text { Meteorological station at Torre del } \\
\text { Filosofo. }\end{array}$ & $\begin{array}{l}\text { Pressure, temperature, relative humidity, } \\
\text { solar radiation flux and wind direction } \\
\text { and speed. }\end{array}$ & $\begin{array}{l}\text { Modelling of the atmospheric } \\
\text { parameters at the ground } \\
\text { level. }\end{array}$ \\
\hline $\begin{array}{l}\text { VIS-IR spectra and rock sampling for } \\
\text { laboratory analyses. }\end{array}$ & $\begin{array}{l}\text { Spectra of volcanic rock, vegetation } \\
\text { and terrain. }\end{array}$ & $\begin{array}{l}\text { Ground truth for surface } \\
\text { reflectance }\end{array}$ \\
\hline
\end{tabular}




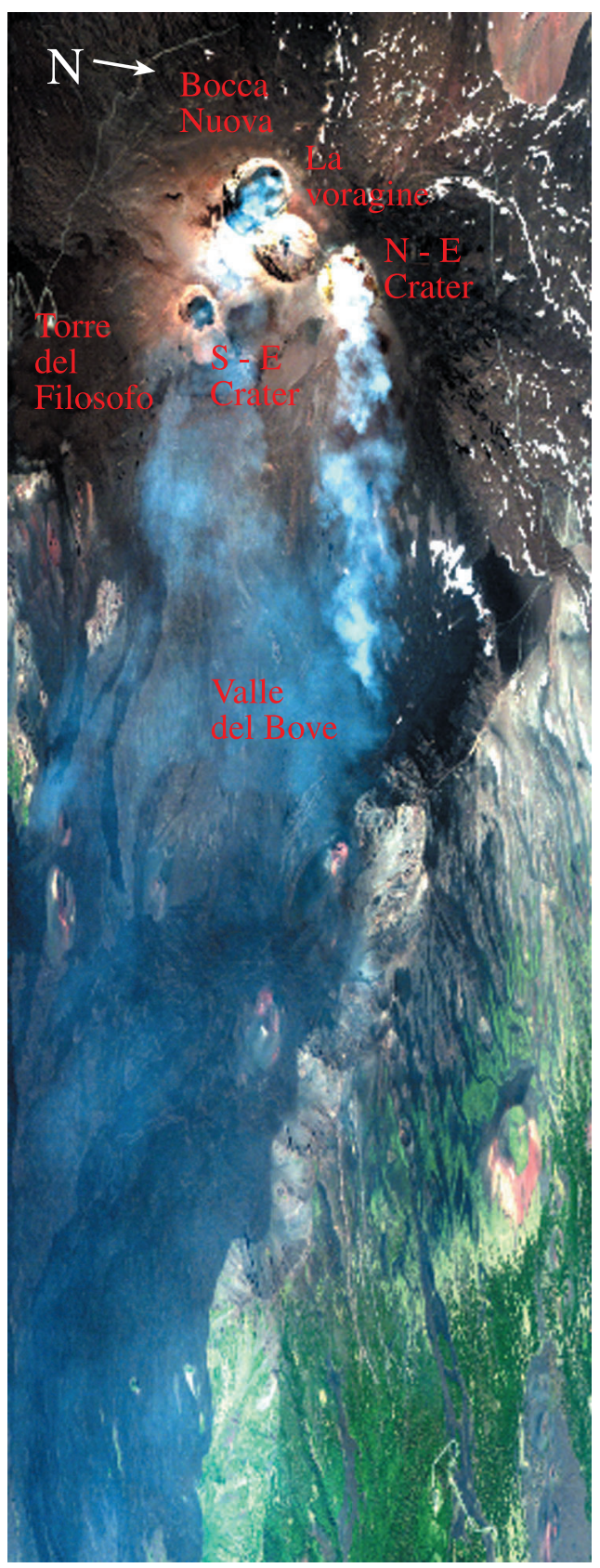

Fig. 2. MIVIS image Etna June 16th 1997 calibrated in Radiance RGB composition. Flight altitude $6000 \mathrm{~m}$. Pixel resolution ranges to $4 \times 4 \mathrm{~m}^{2}$ at summit craters to $11 \times 11 \mathrm{~m}^{2}$ at the sea level.

\subsection{Calibration}

The first step in image processing is the radiometric calibration of the raw data i.e. the conversion of the Digital Numbers $(D N)$ into radiance values, obtained by multiplying pixel by pixel each $D N$ by the calibration factor (Bianchi et al., 1994). The calibration equation for visible and infrared channels is the following:

$$
\begin{aligned}
& R_{i}=\frac{D N_{i}-D N_{\mathrm{REF}_{i}}}{F_{i} \cdot G \cdot A} \\
& i=1, \ldots, 92 \text { channels }
\end{aligned}
$$

where $R_{i}$ is the radiance value, $D N_{i}$ the measured raw data, $D N_{\mathrm{REF}}$ the reference body digital number, $G$ the operational amplifier gain $(1,10,1000$ values), $A$ the attenuation factor (values between 0.4 and 1$)$ and $F_{i}$ the calibration factor. The term $F^{*} G^{*} A$ is constant for the entire flight line and for each channel (Bianchi et al., 1994).

The MIVIS calibration factors were measured with laboratory tests performed before and after the airborne campaign on an optical test bench by using a known radiance source reflected by a panel of know reflectance (Lechi, 2000).

The final result of the radiometric calibration was independently checked using pixels of the calibrated image corresponding to a zone covered by snow situated in Valle del Bove. The snow albedo of selected pixels was calculated inverting the following radiative transfer equation (Spinetti, 2000):

$$
\rho^{*}=\rho_{\text {snow }} \cdot e^{-\tau\left(\frac{1}{\mu_{s}}+\frac{1}{\mu_{V}}\right)}
$$

$\rho^{*}$ is the radiance measured by the sensor given in apparent radiance units $\left(\rho^{*}=\frac{\pi \cdot L}{F_{0} \cdot \mu_{S}}, L\right.$ is the radiance at the sensor, $F_{0}$ is the extraterrestrial solar flux and $\mu_{s}=\cos \theta_{s}$ is the cosine of the solar zenith angle $\left.\theta_{S}\right) ; \rho_{\text {snow }}$ is the snow albedo; $\tau$ is the atmospheric optical depth measured with sunphotometer; $\mu_{V}=\cos \theta_{V}$ is the cosine of the sensor view zenith angle $\theta_{v}$.

The obtained values in the visible range are in agreement with the snow reflectance available in the bibliography (Painter et al., 1996; Salvatori et al., 1997). 


\subsection{DEM coregistration to the image}

The second step in image processing is the definition of the optical path geometry which depends on 3 parameters: target elevation, observer altitude and the viewing angle between the target and the observer (Buongiorno et al., 2002).

The target elevation was determined by use of a Digital Elevation Model (DEM) constructed starting from digital topographic maps at a scale $1: 10000$ and using digital photogrammetric techniques.

The observer altitude and the viewing angle depend on position and attitude of airborne platform, respectively. For each scan line the position of the sensor is estimated with onboard GPS data and the aircraft attitude with onboard gyro and flux gate compass inertial references (Bianchi et al., 1994). The viewing angle was determined taking into account the scanner geometry and the aircraft attitude.

\section{Methodology}

Starting from the radiometrically calibrated image of the plume, a map of volcanic aerosol optical thickness was retrieved. The blue channel (454-474 nm wavelength range) was chosen among the MIVIS channels because it is mostly affected by the aerosol presence. Since the aerosol optical thickness is a decreasing function of wavelength (according to the Ångstrom equation).

To derive the optical thickness, it was necessary to identify and estimate the various contributions that influenced the pixel-measured radiance of the digital image.

\subsection{Radiative transfer}

The method used to retrieve the aerosol optical thickness is based on the hypothesis of cloudless sky and plane parallel atmosphere. Under these assumptions, radiance measured by a remote sensor in the atmosphere is given by the basic radiative transfer equation for monochromatic radiation and no surface emission (Kaufman et al., 1997)

$$
\begin{gathered}
\rho^{*}\left(\theta_{S}, \theta_{V}, \phi_{S}, \phi_{V}\right)=\rho_{a}+\frac{T_{d} \cdot T_{u}}{1-<\rho>\cdot S} \rho+ \\
+\frac{T_{d} \cdot T_{u}}{1-<\rho>\cdot S}<\rho>
\end{gathered}
$$

where the apparent reflectance at the sensor, $\rho^{*}=\frac{\pi \cdot L}{F_{0} \cdot \mu_{s}},\left(L\right.$ is the radiance at the sensor, $F_{0}$ is the extraterrestrial solar flux and $\mu_{s}=\cos \theta_{s}$ is the cosine of the solar zenith angle $\left.\theta_{S}\right) ; \theta_{V}$ is the viewing angle; $\phi_{s}$, $\phi_{V}$ are the solar and view azimuth angle, respectively; $\rho_{a}=\rho_{a}\left(\theta_{S}, \theta_{V}, \phi_{S}, \phi_{V}\right)$ is the radiation scattered into the optical path by the atmosphere (atmospheric path reflectance); $T_{d}\left(\theta_{S}\right)$ is the downward total transmittance in the path from Top Of the Atmosphere (TOA) to the surface (it can be analysed as sum of the direct and the diffuse transmission functions (Sifakis and Deschamps, 1992; Gordon, 1997)); $T_{u}\left(\theta_{V}\right)$ is the upward total transmittance in the path from the ground to the sensor (sum of the direct and the diffuse transmission functions); $\rho$ is the surface reflectance; $\langle\rho\rangle$ is the environmental reflectance; $S$ the atmospheric spherical albedo.

The presence of the volcanic plume modifies eq. (4.1). Each term takes into account the effects due to the different path of the radiation traversing or reflected by the plume (Spinetti, 2000) (see fig. 3). It is important to note that the condition for validity of eq. (4.1) is the low reflectance of the surface (Kaufman et al., 1997). This condition is verified for the selected image. Then eq. (4.1) becomes

$\rho^{*}=\rho_{a}+\rho_{a}^{p}+\rho^{\prime} \cdot \frac{T_{u}^{p} \cdot T_{d}^{p}}{1-<\rho>\cdot S}+<\rho^{\prime}>\cdot \frac{T_{u}^{p} \cdot T_{d}^{p}}{1-<\rho>\cdot S}$

where

$-\rho_{a}=\rho_{a}\left(\theta_{S}, \theta_{V}, \phi_{S}, \phi_{V}\right)$ is the atmospheric path reflectance,

$-\rho_{a}^{p}=\rho_{a}^{p}\left(\theta_{S}, \theta_{V}, \phi_{S}, \phi_{V}\right)$ is the radiation scattered into the optical path by the plume,

$-\rho^{\prime}=\frac{\rho}{1-<\rho>\cdot S} T_{d}\left(\vartheta_{s}\right) \cdot T_{u}\left(\vartheta_{V}\right)$,
$-<\rho^{\prime}>=\frac{<\rho>}{1-<\rho>\cdot S} T_{d}\left(\vartheta_{s}\right) \cdot T_{u}\left(\vartheta_{V}\right)$, 

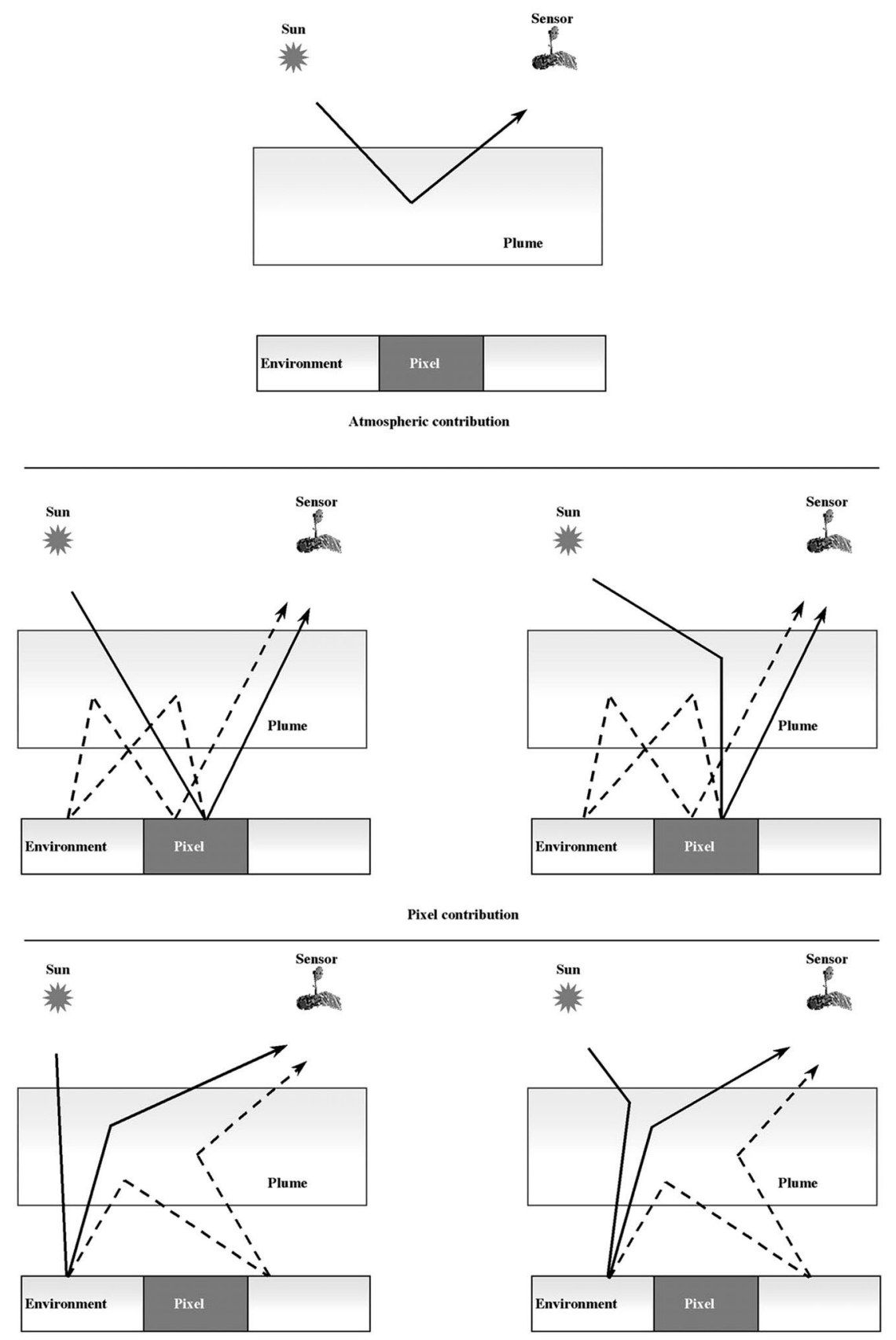

Environment contribution

Fig. 3. Scheme of different solar radiation pathways measured by a remote sensing instrument. 
- $T_{d}^{p}\left(\theta_{S}\right)$ and $T_{u}^{p}\left(\theta_{V}\right)$ are the downward and the upward plume transmittance, respectively, function of volcanic aerosol optical thickness.

In the single-scattering approximation $\rho_{a}^{p}$ the plume path reflectance is given by

$$
\begin{gathered}
\rho_{a}^{p}\left(\theta_{S}, \theta_{v}, \phi_{S}, \phi_{V}\right)=\rho_{m}^{p}+\frac{\omega_{0} \cdot P\left(\psi_{S}\right)}{4\left(\mu_{S}+\mu_{V}\right)} . \\
\cdot\left\{1-\exp -\left[\frac{\tau^{a}}{\mu_{S}}+\frac{\tau^{a}}{\mu_{V}}\right]\right\}
\end{gathered}
$$

$\rho_{m}^{p}=\rho_{m}^{p}\left(\theta_{S}, \theta_{v}, \phi_{S}, \phi_{V}\right)$ is the molecular scattering path reflectance, $\omega_{0}$ single-scattering albedo, $P\left(\psi_{s}\right)$ phase function and $\tau^{a}$ the volcanic aerosol optical thickness; $\mu_{V}$ and $\mu_{s}$ are cosines of the view and illumination directions, respectively.

\subsection{Inversion technique}

In order to invert the eq. (4.2) and extract the aerosol optical thickness $\tau^{a}$, it is necessary to estimate the atmospheric terms for each pixel of the MIVIS image. To this aim, the 6S (Second Simulation of the Satellite Signal in the Solar
Spectrum) radiative transfer code (Vermonte et al., 1997) was used. The model was calibrated using atmospheric optical thickness measurement simultaneous with the selected image.

The Digital Elevation Model (DEM) was used to take into account the elevation of each pixel for a correct estimation of atmospheric transmittance in the inversion procedure.

Moreover, the inversion procedure needed the knowledge of the surface albedo and the ground inclination of each pixel with respect to the sun and sensor relative positions. Ground albedo was measured during the campaign (table III): an average value of 0.05 for spectral basaltic lava in the wavelength range 454-474 $\mathrm{nm}$ was retrieved from field measurements (fig. 4). The ground inclination was obtained from the shadow digital model (Shaded Relief) using the DEM and the geometrical factors of the source, such as solar zenith and azimuth angles. The inclination was interpolated from the elevation of each pixel of the DEM and the altitudes of the nearest neighbours pixels (Horn et al., 1989).

The low reflectance of basaltic lava permits to neglect the environmental term in the eq. (4.2).

Before inverting eq. (4.2), a digital mask was applied to the image in order to isolate the pixels belonging to the plume.

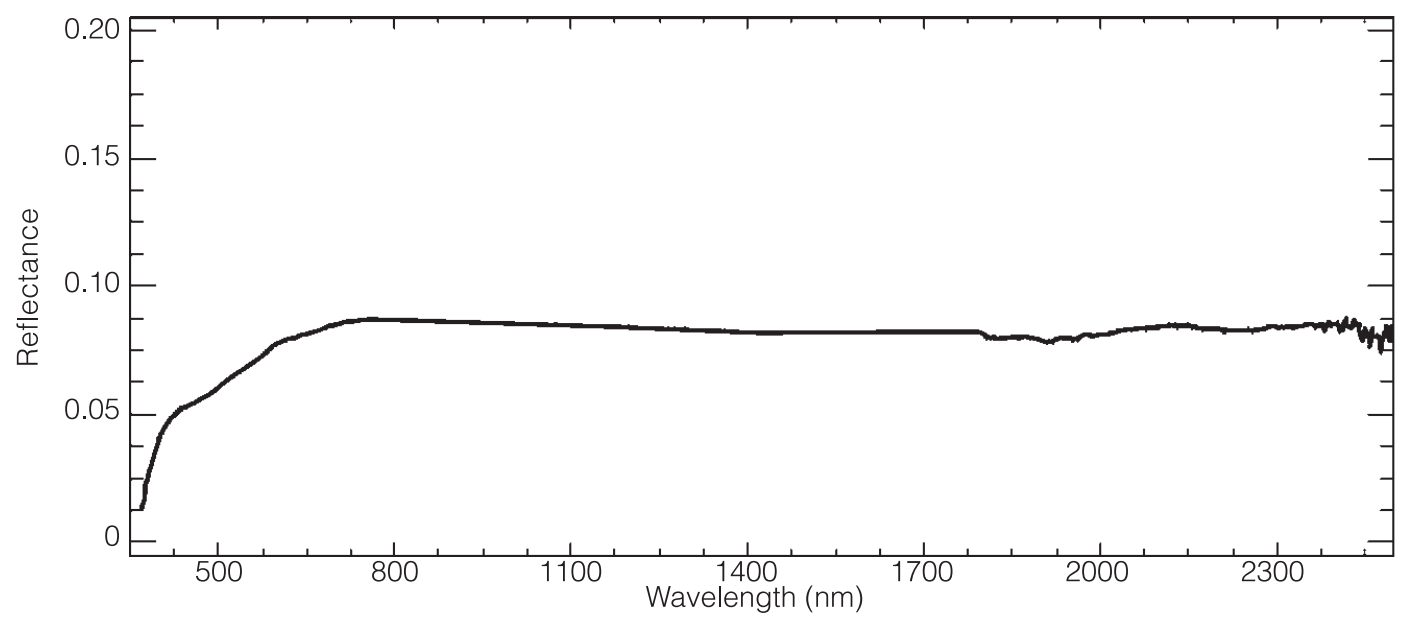

Fig. 4. Volcanic rock reflectance measured in laboratory and during MVRSS «Sicily 1997» campaign on Mt. Etna (1972 lava flow). Reflectance value of 0.05 in wavelength range 454-474 nm. 


\section{Results and conclusions}

The map in fig. 5 shows results of the inversion procedure, indicating the spatial distribution of volcanic aerosol optical thickness. The $\tau^{a}$ values range from a minimum of 0.1 in the far part of the plume, to a maximum of 0.3 , close to the summit craters.

This result cannot be validated by the direct optical measurements across the plume since they are not available. However, a comparison can be made with the sunphotometric measurements taken in Torre del Filosofo in October 1997 (Oppenheimer, 1998) assuming similar aerosol burden in this two periods. This is a reasonable assumption because Mt. Etna had similar quiescent conditions in the June and in October 1997 as deduced by the International Institute of Volcanology observations (Coltelli and Del Carlo, 1997). Moreover, also the $\mathrm{SO}_{2}$ flux shows similar values in these two periods as emerges from the monitoring of weekly measurements performed using COSPEC correlation spectrometer (Caltabiano et al., 1994) on adapted vehicle and from fixed observation sites (Buongiorno et al., 1999). Conversely, the time weather conditions for October 26th with respect to June 16th 1997 are different in temperature (about $12{ }^{\circ} \mathrm{C}$ lower) and in relative humidity (about 25\% higher) while they are similar for the wind speed and direction. Recent studies (Watson et al., 2001) point out that meteorology play same role in the volcanic aerosol formation but it is not as significant as the volcanic activity.

Figure 6 reports the retrieved $\tau^{a}$ range and shows a rather good agreement with sunphotometric measurements (Oppenheimer, 1998).

This work represents a preliminary and promising study to investigate the aerosol load in volcanic plume with remote sensing techniques. Validity of this algorithm is for thin and tropospheric plume, such as the Etna plume in quiescent condition (Teggi et al., 1999). To investigate explosive and tropospheric volcanic plume, the inversion algorithm needs a different implementation taking into account the multiple scattering on the path radiance term in eq. (4.3).

In the near future, it is foreseen to extract from digital images more information on the

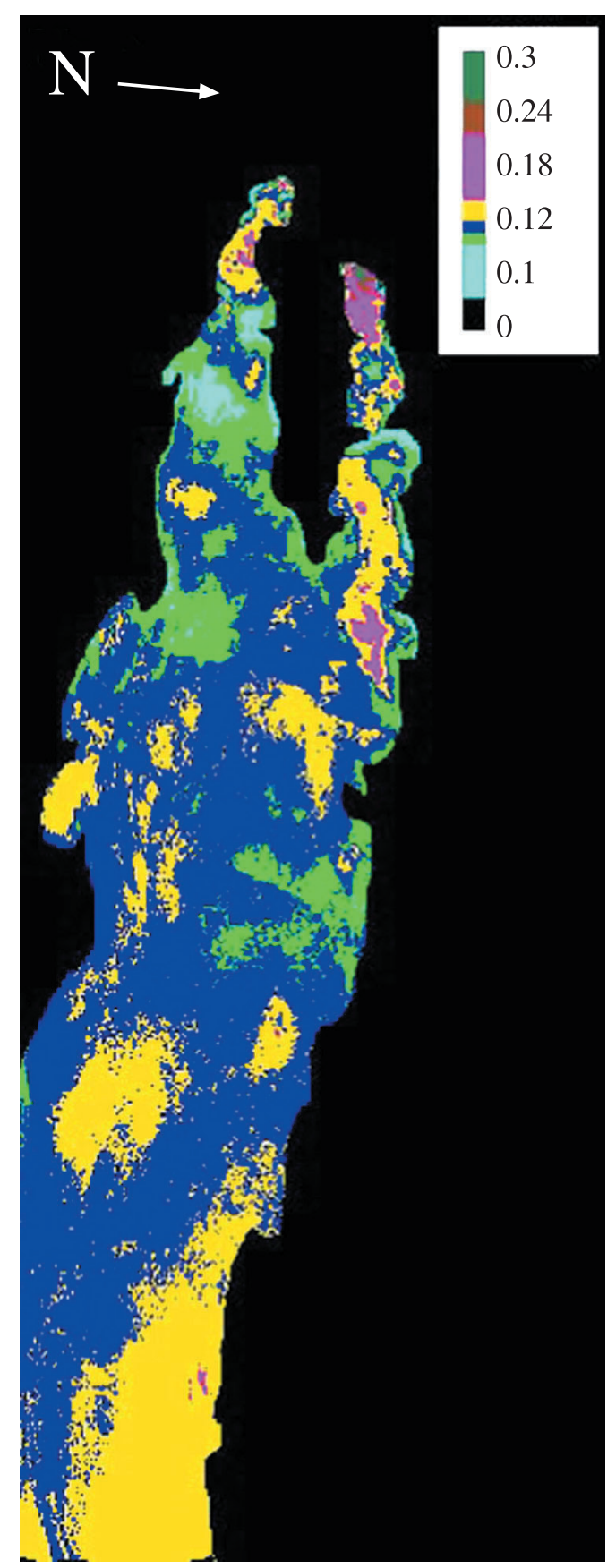

Fig. 5. Resulting map of volcanic plume aerosol optical thickness $\left(\tau^{a}\right)$ in false colours. Average value of spatial distribution $\tau^{a}=0.1$. 


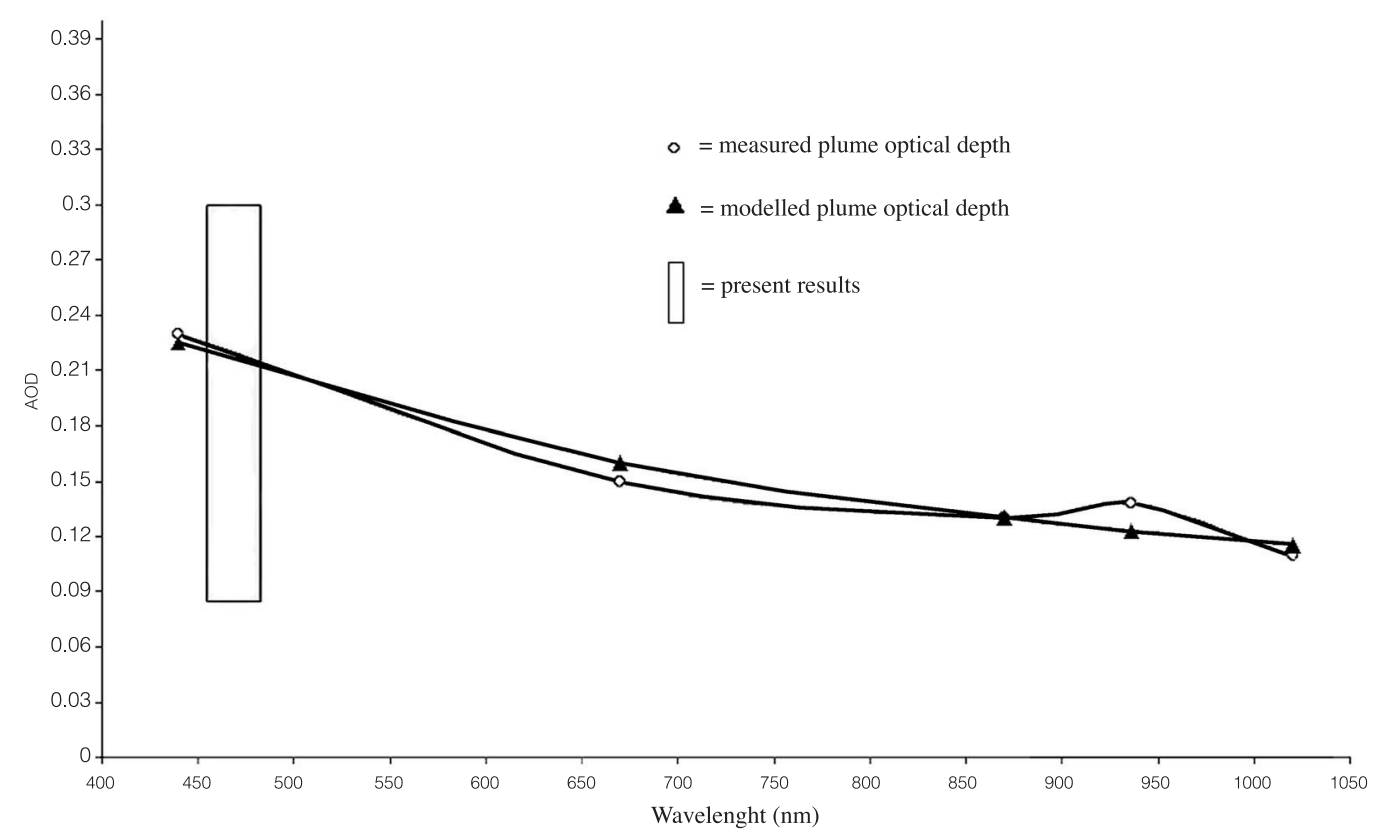

Fig. 6. Solid lines indicate the $\tau^{a}$ measured by sun-photometer (October 26th, 1997) and $\tau^{a}$ modelled using aerosol code (Oppenheimer, 1998). The rectangle indicates the $\tau^{a}$ range obtained from the inversion procedure of MIVIS data (June 16th, 1997).

plume particles. For this purpose, $\tau^{a}$ will be calculated at different MIVIS visible channels. All these $\tau^{a}$ values could be used to derive particle optical characteristics, such as the Angstrom coefficients, and an estimation of particle size.

However, the development and the validation of a remote sensing technique, as most of the inverse problems, requires input information on atmospheric and surface parameters, such as the meteorological and atmospheric parameters. It is important to measure these parameters simultaneously. The MVRRS project plans to install a ground-based photometer instrument that will record atmospheric and plume data continuously. These data will serve to develop and validate the remote sensing techniques.

The future work will regard the development of a suitable methodology, combining remote sensing data, ground-based data and atmospheric modelling to systematically study the volcanic plumes characteristics.

\section{Acknowledgements}

The work was developed during a Thesis on Physics, «La Sapienza», University of Rome. The work was carried out at INGV, partially funded by GNV and ASI. The European Community (MVRSS project, Contract n. ENV4-CT96-0288) funded the MIVIS 1997 campaign.

We wish to thank particularly Prof. G. Fiocco for his helpful advice. We thank the reviewer for his thorough and helpful reviews.

\section{REFERENCES}

Allard, P., J. Carbonelle, D. DaJlevic, J. Le Bronec, P. Morel, M.C. Robe, J.M. MAURENAS, R.F. PIERRET, D. MARTins, J.C. SABRouX and P. ZetTwoog (1991): Eruptive and diffuse emission of $\mathrm{CO}_{2}$ from Mount Etna, Nature, 351, 387-391.

Amman, M., L. SChERRER, W. Mueller, H. Burtscher and H.C. SIEGMANN (1992): Continuous monitoring of ultrafine aerosol emissions at Mt. Etna, Geophys. Res. Lett., 19 (13), 1387-1390. 
BiAnCHI, R., C.M. MARINO and S. PIGNATTI (1994): Airborne hyperspectral remote sensing in Italy, in Proceedings of the European Symposium on Satellite Remote Sensing, Rome, Italy, September 26-30, 1994, EUROPTO Series, SPIE, vol. 2318, 29-37.

Buongiorno, M.F., M.P. Bogliolo, T. Caltabiano, V. Carrere, S. Corradini, L. Merucci, S. Pugnaghi, S. SAlvi, A. Sterni and S. Teggi (1999): MVRRS Campaign: MIVIS mission on Sicilian volcanoes and ground measurements, Quad. Geofis. (INGV, Rome), n. 7, 1-90

BUONGIORNO, M.F., V.J. REALMUTO and F. DOUMAZ (2002): Recovery of spectral emissivity from thermal infrared multispectral scanner imagery over a mountainous terrain: a case study from Mount Etna, Remote Sensing Environ., 79, 123-133.

Caltabiano, T., R. Romano and G. Budetta (1994): SO flux measurements at Mount Etna (Sicily), J. Geophys. Res., 99, 12,809-12,819.

Coltelli, M. and P. Del CARlo (1997): Summary of 1997 activity at Etna Volcano, Internal Report, Istituto Nazionale di Geofisica e Vulcanologia, Sezione di Catania.

CHIN, M. and D.J. JACOB (1996): Anthropogenic and natural contributions to tropospheric sulphate: a global model analysis, J. Geophys. Res., 101 (D13), 18,691-18,699.

FiocCO, G., D. FuÀ and G. Visconti (1994): The Mount Pinatubo eruption effects on the atmosphere and climate, NATO ASI Series 1: Global Environmental Change, 42 , pp. 310.

FRANCIS, P., M.R. BURTON and C. OPPENHEIMER (1998): Remote sensing of volcanic gas composition by solar occultation spectroscopy, Nature, 396, 567-570.

GoRDON, H.R. (1997): Atmospheric correction of ocean color imagery in the Earth observing system era, J. Geophys. Res., 102 (D14), 17,081-17,106.

Hansen, J., A. LACIS, R. RuEdy and M. SATo (1992): Potential climate impact of Mount Pinatubo eruption, Geophys. Res. Lett., 19, 215-218.

HORN, B.K.P. and M.J. BROOKS (1989): Shape for Shading (The MIT Press, Cambridge), pp. 577.

JAESCHKE, W., H. BERRESHEIM and H. GEORGH (1982): Sulfur emission from Mount Etna, J. Geophys. Res., 87 (C9), 7253-7261.

Kaufman, Y.J., D. TAnRÉ, L.A. Remer, E.F. Vermote, A. CHU and B.N. HolBEN (1997): Operational remote sensing of tropospheric aerosol over land from EOS moderate resolution imaging spectroradiometer, $J$. Geophys. Res., 102 (D14), 17,051-17,067.

LECHI, G. (2000): Relazione Finale Contratto «Calibrazione Radiometrica su 102 Canali Distribuiti fra le Bande del Visibile all'Infrarosso Termico dello Scanner Aereotrasportato MIVIS del CNR», Politecnico di Milano, Dipartimento IIAR, Sezione Rilevamento.
McClelland, L., T. Simkin, M. Summers, E. Nielsen and T.C. STEIN (1989): Global volcanism 1975-1985 (Engelwood Cliffs, NJ: Prentice-Hall), pp. 655.

NeubaUer, K.R., T.S. Sum and V.J. MurRAY (1996): Sulphur speciation in individual aerosol particles, $J$. Geophys. Res., 101 (D13), 18,701-18,707.

OPPENHEIMER, C. (1998): RDT programme environment and climate, MVRSS Mitigation of Volcanic Risk by Remote Sensing, Second Term Scientific Progress Report of Contract n. ENV4-CT96-0288.

PAINTER, T.H., D.A. RoberTs, R.O. GREEN and J. DOZIER (1996): Subpixel snow covered area and snow grain size from mixture analysis with AVIRIS data, in Sixth Annual JPL Airborne Earth Science Workshop, edited by R.O. GREEN, JPL Publication 96-4, vol. 1, 185-188.

ROMANO, R. and C. STURIALE (1982): The historical eruption of Mt. Etna (volcanological data), Mem. Soc. Geol. Ital., 23, 75-97.

SAlvatori, R., R. CASACCHIA and S. GHERGo (1997): Sispec: snow and ice spectra archive, Rivista Italiana di Telerilevamento, 9 (AIT Editor).

SIFAKIS, N. and P.Y. DESCHAMPS (1992): Mapping of air pollution using SPOT satellite data, Photogramm. Eng. Remote Sensing, 58 (10), 1433-1437.

Sparks, R.S.J., M.I. BuRsiK, S.N. CAREY, J.S. GILbERT, L.S. GLAZE, H. SiguRdSSON and A.W. WOODS (1997): Volcanic Plumes (John Wiley and Sons, New York), pp. 574.

SPINETTI, C. (2000): Caratterizzazione ottica di una piuma vulcanica mediante telerilevamento aereo, Ph.Thesis, Dipartimento di Fisica, Università «La Sapienza», Roma.

SYMONDS, R.B., W.I. Rose, G.J.S. BLUTH and T.M. GERLACH (1994): Volcanic-gas studies: methods, results, and applications, in Volatiles in Magmas, edited by M.R. CArroll and J.R. Holloway, Mineral. Soc. Am., Rev. Mineral., 30, 1-66.

Teggi, S., S. Pugnaghi, M.P. Bogliolo, M.F. BuOngioRno and V.J. REALMUTO (1999): Modelling local atmospheric effects by MODTRAN-3 code and vertical profile in the area of Mt. Etna volcano, Sicily, J. Atmos. Solar Terr. Phys., 60, 1059-1070.

VERmonte, E., D. TANRÉ, J.L. DeuZÉ, M. HeRman and J.J. MORCRETTE (1997): Second simulation of the satellite signal in the solar spectrum (6S): user's guide, Technical Report Version 2, Department of Geography, University of Maryland, c/o NASA-Goddard Space Flight CenterCode 923, Greenbelt, MD 20771, USA, pp. 218.

WATSON, I.M. and C. OPPENHEIMER (2000): Particle size distributions of Mount Etna's aerosol plume constrained by sun photometr, J. Geophys. Res., 105 (D8), 9823-9829.

WATSON, I.M. and C. OPPENHEIMER (2001): Photometric observations of Mt. Etna's different aerosol plumes 2001, Atmos. Environ., 35 (21), 3561-3572. 